\title{
PROCEDIMIENTOS COLECTIVOS EN EL DERECHO COMPARADO LATINOAMERICANO: EL CASO DE CHILE Y MÉXICO
}

\author{
RODRIGO GONZÁLEZ QUINTERO
}

ANDRÉS SARMIENTO LAMUS 
SUMARIO.

INTRODUCCIÓN. I. EXPANSIÓN DE LOS MECANISMOS PROCESALES DE CLASE O GRUPO. II. APROXIMACIÓN CAUTELOSA A LOS PROCEDIMIENTOS COLECTIVOS: POSIBILIDAD DE ABUSO Y DESEQUILIBRIO. III. NATURALEZA PROBLEMÁTICA DE LOS PROCEDIMIENTOS COLECTIVOS. IV. ELEMENTOS Y ASPECTOS DISTINTIVOS DE LOS PROCEDIMIENTOS COLECTIVOS. V. RÉGIMEN JURÍDICO DE LAS ACCIONES DE CLASE EN ESTADOS UNIDOS. VI. PROCEDIMIENTOS COLECTIVOS EN CHILE. VII. PROCEDIMIENTOS COLECTIVOS EN MÉXICO. VIII. RECAPITULACIÓN Y CONCLUSIONES. 


\title{
PROCEDIMIENTOS COLECTIVOS EN EL DERECHO COMPARADO LATINOAMERICANO: EL CASO DE CHILE Y MÉXICO
}

\author{
RODRIGO GONZÁLEZ QUINTERO ${ }^{1}$ \\ ANDRÉS SARMIENTO LAMUS²
}

\section{INTRODUCCIÓN}

En las últimas décadas las acciones de clase, o su equivalente en el Derecho Comparado que pueden denominarse como procedimientos colectivos, han sido establecidas en distintas jurisdicciones del mundo. Son mecanismos procesales que permiten a una o varias personas, o una entidad, representar a un grupo numeroso de individuos en situación parecida en una demanda cuyo objeto es una indemnización. ${ }^{3}$ La relevancia del tema a abordar en el presente artículo, se da a partir de dos factores que pueden calificarse como de 'expansión' uno y de 'limitación' el otro. Si bien se aprecia un fenómeno de «expansión» de tales instrumentos procesales —es decir su propagación en distintos países-, también es cierto que su regulación presenta tendencias si no restrictivas o limitadoras, al menos si contextualizadoras tanto en el plano normativo como jurisprudencial. Tendencias que encuentran justificación, precisamente, en evitar los usos abusivos, frívolos e injustos de la acción, así como también las consecuencias económicas irrazonables que se le atribuyen. De allí las frecuentes referencias doctrinales a dichas acciones en las que son calificadas como «el lobo feroz» que

1 Calle 74 \# 14-14. BOGOTA D.C., COLOMBIA. Doctor en Derecho (J.S.D) y Magíster en Derecho (LL.M), Washington University in St. Louis. Profesor-Investigador de la Universidad Sergio Arboleda- Bogotá. Los autores agradecen a la Agencia Nacional de Defensa Jurídica del Estado-Colombia la oportunidad para desarrollar la investigación contenida en el presente artículo. Email: rodrigo. gonzalez@usa.edu.co

2 Andrés Sarmiento Lamus. Calle 74\#14-14. Bogotá D.C., COLOMBIA. Doctor en Derecho (Ph.D) y Magíster en Derecho (LL.M.) Leiden University. Profesor-Investigador de la Universidad Sergio Arboleda. Email: andres.sarmiento@usa.edu.co

3 Deborah Hensler, «From Sea to Shining Sea: How and Why Class Actions are Spreading Globally», Kansas Law Review, vol. 65., 2017, p. 966. 
permite «conciliaciones extorsivas», y que lleva a resultados «terribles»y «absurdos».

En ese orden de ideas, un estudio de derecho público comparado permite enmarcar a los regímenes de procedimientos colectivos en Chile y México dentro de los fenómenos descritos de 'expansión-generalización' y también de 'contextualización-limitación’. Para llegar a dicha conclusión, el presente artículo se aproxima a los procedimientos colectivos desde la doctrina — la cual reconoce su potencial carácter problemático y hace un llamado a la cautela para prevenir así abusos y desequilibrios, identificando además elementos que podrían restringir éstos y aquellos-, así como hace referencia también al modelo jurídico de las acciones de clase de los Estados Unidos —el cual se entiende como origen de tales procedimientos en el iuscomparativismo - en donde se aprecia una tendencia limitadora desde las normas y la jurisprudencia. Luego explicará la regulación normativa y las aproximaciones judiciales sobre la figura en Chile y México, de manera que la conclusión permite identificar similitudes entre la práctica de éstos países y las tendencias doctrinales.

\section{EXPANSIÓN DE LOS MECANISMOS PROCESALES DE CLASE O GRUPO}

Alrededor del mundo individuos, organizaciones, asociaciones y entes públicos acuden con frecuencia a los tribunales de justicia para solicitar la solución de daños cuya afectación es colectiva; daños causados a partir de productos defectuosos, por afectación del medio ambiente, pérdidas financieras derivadas de infracciones a la competencia, entre otros. ${ }^{4}$ Así, la ocurrencia de estas situaciones dañinas es lo que ha propiciado la expansión general del instrumento procesal que permite las reclamaciones colectivas.

En ese sentido durante las últimas décadas las acciones de clase, es decir aquél procedimiento por el que una persona u organización litiga en representación de un grupo o de un interés colectivo, se han extendido por el mundo con diferentes denominaciones —acción colectiva, remedio colectivo o acción popular- siempre recordando su parecido para con la class action estadounidense. ${ }^{5}$ La acción de clase moderna, fruto de la revisión de la Regla 23 del Procedimiento Civil Federal realizada en el año 1966 en Estados Unidos, estableció nuevas oportunidades para demandantes así como nuevas amenazas también para demandados institucionales, pues la interpretación de

4 Deborah Hensler, «The Globalization of Class Actions», The Annals of the American Academy of Political and Social Sciences, vol. 622, 2009, p. 8. S.I. STrONG, «Large Scale Dispute Resolution in Jurisdictions without Judicial Class Actions: Learning from the Irish Experience», ILSA Journal of International and Comparative Law, vol. 22, 2016, p. 341.

5 Deborah Hensler, «The Global Landscape of collective Litigation», en: Deborah Hensler y Christopher Hodges (eds.), Class Actions in Context: How Culture, Economics and Politics shape collective Litigation. Northampton, Elgar, 2016, p. 9. 
la norma permite que un abogado represente a cientos de miles de personas que hayan experimentado un tratamiento similar por el potencial demandado. Los miembros de la clase o grupo no tienen que haber buscado ni contratado al abogado; siempre que sus circunstancias sean suficientemente similares y que su situación viole la norma relevante, el abogado del grupo demandante podrá litigar en su nombre. ${ }^{6}$

Así, lo que antes se entendía como una disputa llevada al juez entre dos individuos, entre un individuo y una empresa, o entre un individuo y el Estado - las cuales no siempre podían merecer remedio legal—, se reputan ahora como luchas grupales en contra de empresas o el Estado cuya pertinencia amerita resolución judicial. ${ }^{7}$ Es por ello que hasta hace poco ese modelo de class action era una invención americana única, resistida — si es que no rechazada - por la mayoría de los sistemas jurídicos contemporáneos. ${ }^{8}$ Ahora bien, una parte de ese fenómeno global se refleja en América Latina donde también se han adoptado figuras procesales para litigios colectivos tales como las acciones populares y de grupo en Colombia, acciones colectivas y difusas en México, ${ }^{9}$ y acciones colectivas en Chile. ${ }^{10}$

\section{APROXIMACIÓN CAUTELOSA A LOS PROCEDIMIENTOS COLECTIVOS: POSIBILIDAD DE ABUSO Y DESEQUILIBRIO}

Como ya se ha dicho antes, la figura de los procedimientos colectivos se origina a partir de las class actions norteamericanas, modelo que ha sido resistido en otras jurisdicciones. ${ }^{11}$ Es un modelo de procedimiento civil calificado como pro-deman-

6 Stephen Yeazell, Lawsuits in a Market Economy: The Evolution of Civil Litigation, Chicago, The University of Chicago Press, 2018, p. 70.

7 Deborah HensLer, «The Globalization of Class Actions», Op. cit., p. 8.

8 Linda Mullenix, «Ending Class Actions as we Know Them», Emory Law Journal, vol. 64, 2014, p. 401.

9 Sobre los procedimientos colectivos en el derecho mexicano y su posible similitud o diferenciación de Estados Unidos ver la obra de Ovalle. José Ovalle, «Legitimación en las Acciones Colectivas», Boletín Mexicano de Derecho Comparado, núm. 138, 2013; José Ovalle, «Las Acciones Colectivas en el Código Federal de Procedimientos Civiles», Revista de Derecho Privado, núm. 7, 2015. También se puede consultar el libro de Ferrer y Gidi. Eduardo Ferrer y Antonio Gidi (coord.), La Tutela de los Derechos Difusos, Colectivos e Individuales Homogéneos: Hacia un Código Modelo para Iberoamérica, México D.F., Porrúa, 2003.

10 Sobre los procedimientos colectivos en el derecho chileno y su posible similitud o diferenciación de Estados Unidos ver la obra de Barroilhet y la de Gubbins. Agustín Barroilhet, «Class Actions in Chile», Law and Business Review of the Americas, vol. 18, 2012, p. 277; Martín GubBins y Carla LópeZ, «Chile», The Annals of the American Academy of Political and Social Sciences, vol. 622, 2009. También se puede consultar el libro de Ferrer y Gidi. Eduardo Ferrer y Antonio GIDI (coord.), La Tutela de los Derechos Difusos, Colectivos e Individuales Homogéneos: Hacia un Código Modelopara Iberoamérica, México D.F., Porrúa, 2003.

11 Así el profesor Strong afirma que «numerosos países, incluidos muchos que antes criticaban y condenaban el modelo estadounidense de acciones de clase, ahora han adoptado varias formas de remedio colectivo. S.I. Strong, «Large Scale Dispute Resolution in Jurisdictions without Judicial Class Actions: Learning from the Irish Experience», Op. cit., p. 341. También los profesores Baker y Freynes han hecho 
dante, entre otras razones porque contempla juicios por jurado en donde la decisión última recae en un cuerpo no profesional guiado por un juez profesional; también porque las sentencias que pueden incluir altas sumas dinerarias, alimentadas por daños punitivos. Adicional a esto, la posibilidad de cuota litis hace bastante rentables para los abogados las demandas por daños. ${ }^{12}$ Según datos entregados por Silver, sólo a nivel federal en Estados Unidos los litigios por éstas acciones ascienden a más de veinte mil millones de dólares anuales, que en su mayoría se entregan como honorarios a los abogados. ${ }^{13}$ A manera de ejemplo, dichos honorarios en el $72 \%$ de casos llevados a tribunales federales entre los años 2009 a 2013, oscilaron entre el $25 \%$ y el $34 \%$ de las indemnizaciones entregadas a los demandantes. ${ }^{14}$

Por ello cabría afirmar que las class actions en Estados Unidos son unos artefactos con propiedades alquimistas, dado que permiten convertir reclamaciones insignificantes en otras que son bastante amenazantes. Y esto en virtud del lucro enorme que representan para el abogado, puesto que la regulación permite a éste cobrar una tasa de la suma recuperada en nombre de la clase; tasa que presenta una complicación ética enorme, pues en la acción de clase el abogado no responde ante un cliente que tiene capacidad de decisión sobre los términos de una conciliación eventual — como si ocurre en otros procesos civiles_-; factor decisional determinado por el hecho que la clase demandante no suele tener estructura organizacional que le permita tomar decisiones sobre conciliaciones, dejando que el abogado asuma dicho rol. ${ }^{15}$

Cualquier tipo de norma sectorial de derecho sustantivo - por ejemplo, protección del consumidor - diseñada para que una persona pueda obtener resarcimiento normal y que pueda pagar a su representación técnica, y que también busca empoderar al público para controlar a aquellos que han transgredido el ordenamiento jurídico, puede convertirse en un instrumento aterrador mediante la class action. ${ }^{16}$

Las acciones grupales facilitan y regulan la consolidación de varias demandas similares en una sola, y aunque — como se ha dicho— han sido adoptadas en otros países, es en el mercado legal norteamericano donde se usan en toda su extensión. Y

referencia a la resistencia de la Comisión y el Parlamento europeos respecto de implantar modelos de reclamación colectivos siquiera parecidos al estadounidense. George BAKER y Pierre FreYnES, «The Economics of the European Commission's Recommendation on Collective Reddress», en: Eva Lein y Duncan Fairgrieve (eds.), Collective Redress in Europe - Why and How?, London, British Institute of International and Comparative Law, 2015, p. 7.

12 R.L Marcus, «The Big Bad Wolf: American Class Actions», en: Victoria Harsagi y C. Van Rhee, (eds.) Multiparty Redress Mechanisms in Europe, Cambridge, Intersentia, 2013, p. 36.

13 Charles SIlver, «Is the Price Right? An Empirical Study of Fee-Setting in Securities Class Actions», Columbia Law Review, vol. 115, 2015, p. 1373.

14 Geoffrey Miller, Theodore Eissemberg y Roy Germano, «Attorneys' Fees in Class Actions 2009-2013", New York University School of Law - Law and Economics Research Paper Series, No. 17-02, 2016 , p. 16.

15 Stephen Yeazell, Lawsuits in a Market Economy: The Evolution of Civil Litigation, Op. cit., pp. $70-71$.

16 R.L Marcus, «The Big Bad Wolf: American Class Actions», Op. cit., p. 39. 
el principal argumento a favor de su utilización es simple, ya que probablemente es más eficiente litigar la misma controversia general una sola vez, que hacerlo en una serie numerosa de controversias similares; un solo juicio frente a varios juicios individuales. ${ }^{17}$

Pese a lo atractivo de una afirmación tan simplista, las class actions no han logrado un consenso general sobre su conveniencia, entre otras razones por sus consecuencias económicas; de un lado, se reputa como práctica social beneficiosa que permite remedios apropiados para pequeñas reclamaciones contra demandados poderosos, pero de otro implica un costo social que promueve litigios frívolos que amenazan con erosionar la confianza y la competencia empresariales. ${ }^{18}$ Los elementos adscritos a las acciones de clase estadounidenses evidencian su problemática, de manera tal que «los sistemas jurídicos de derecho civil podrían incorporar procedimientos de reclamaciones grupales, aunque no pueden trasplantar el modelo de class actions estadounidense sin una adaptación sustancial.» ${ }^{19}$ En ese sentido, el trasplante jurídico de ese tipo de acciones — de acuerdo con Hensler - se ha dado bien para emular o para evitar el modelo de Estados Unidos. ${ }^{20}$

Sin embargo, es pertinente esbozar una aclaración; el modelo de class actions estadounidense ha florecido en sistema judicial específico con jurados, firmas de abogados grandes, abogados con honorarios tasados vía cuota litis, jueces con amplios poderes de control constitucional y tribunales supremos que establecen sus propias reglas procedimentales y cuentan con discreción para seleccionar los casos que resuelven. Es un modelo incrustado en una cultura del common law y en un contexto constitucional de economía de mercado, que no está limitado por garantías o derechos sociales ni objetivos del Estado de Bienestar. Las culturas jurídicas europeas — y por añadidura las latinoamericanas - , por otro lado, han desarrollado otro tipo de remedios colectivos, que resaltan el protagonismo del Derecho Público y las instituciones básicas del modelo de bienestar estatal, como por ejemplo la obligatoriedad de pólizas de seguros. $^{21}$

17 Thomas Ulen, «The Economics of Class Action Litigation», en: Jurgen Backhaus y Alberto Cassone, (eds.), The Law and Economics of Class Actions in Europe, Northampton, Elgar, 2012, p. 75.

18 Ibidem, pp. 75-76.

19 Antonio GIDI, «Class Actions in Brazil: A Model for Civil Law Countries», American Journal of Comparative Law, vol. 51, 2003, p. 314.

20 Deborah Hensler, «From Sea to Shining Sea: How and Why Class Actions are Spreading Globally», Op. cit., p. 968.

${ }^{21}$ Jorg LuTHER, «The Constitutional Impact of Class Actions in European Legal Systems», en: Jurgen Backhaus y Alberto Cassone, (eds.), The Law and Economics of Class Actions in Europe, Northampton, Elgar, 2012, pp. 309-310. 


\section{NATURALEZA PROBLEMÁTICA DE LOS PROCEDIMIENTOS COLECTIVOS}

Al considerar el impacto problemático de las class actions en la democracia de los Estados Unidos contemporáneos —el cual ha suscitado esfuerzos constantes tanto desde el legislativo como desde los tribunales para limitar su alcance ${ }^{22}$ - es importante recordar un elemento capital, y es que éstas no fueron concebidas en sus inicios como mecanismo procesal cuyo propósito sea hacer justicia, ni para servir de instrumento policivo contra conductas empresariales o redistribución de la riqueza. Por el contrario, su objeto no es más que servir como aparato procesal que facilita la aplicación de normas sustantivas preexistentes. Tales normas sustantivas —en áreas como la competencia, consumo y finanzas - aplicadas mediante class actions, tienen como rasgos distintivos de un lado la prohibición o regulación de ciertos comportamientos, y del otro la previsión de remedios o compensaciones que resulten de la ejecución de tales regulaciones. ${ }^{23}$ Es por ello que ciertas tecnicidades procesales alimentan la crítica a las acciones grupales y permiten cuestionar la posibilidad real de funcionamiento en sistemas jurídicos diferentes al norteamericano. ${ }^{24}$

Existen dos razones principales para establecer normas que habiliten el ejercicio de acciones grupales. La primera descansa en la realización efectiva de la justicia, en cuanto es medio que permite compensar a quienes han sufrido daños causados por actores poderosos, en situaciones de productos o servicios defectuosos, fraude en precios, contaminación ambiental, etcétera. La segunda radica en desincentivar actuaciones ilegales, que escapan al control de las autoridades, o cuyo castigo es insuficiente. ${ }^{25}$ En ese sentido, desde el punto de vista económico se propician dos bienes instrumentales que se identifican en la protección de las víctimas y las ganancias para el abogado, y se produce además un bien objetivo representado en el desistimiento de comportamientos indeseados de infractores potenciales, que conllevan a la promoción de la eficiencia. ${ }^{26}$

Las acciones grupales confrontan así a dos teorías económicas; la primera es la teoría de aplicación y cumplimiento de la ley, en la que juegan un rol social positivo en cuanto incentivan a que potenciales transgresores del ordenamiento jurídico se abstengan de hacerlo. La segunda es la teoría de la captura, en la que estas acciones

22 Stephen Burbank y Sean Farhang, «Class Actions and the Counterrevolution Against Federal Litigation», University of Pennsylvania Law Review, vol. 165, 2017, p. 1528.

23 Martin Redish, Wholesale Justice: Constitutional Democracy and the Problem of the Class Action Suit, Stanford, Stanford University Press, 2009. pp. 22-23.

24 Alberto Cassone y Giovanni Ramello, «Private Club and Public Goods: the Economic Boundaries of Class Action Litigation», en: Jurgen Backhaus y Alberto Cassone, (eds.), The Law and Economics of Class Actions in Europe, Northampton, Elgar, 2012, p. 103.

25 Frederic Scherer, «Class Actions in the US Experience: An Economist's Perception», en: Jurgen Backhaus y Alberto Cassone, (eds.), The Law and Economics of Class Actions in Europe, Northampton, Elgar, 2012, p. 27.

26 Alberto Cassone y Giovanni Ramello, «Private Club and Public Goods: the Economic Boundaries of Class Action Litigation», Op. cit., p. 102. 
promueven litigios oportunistas y temerarios, jugando un papel social negativo. Este último problema aparece cuando abogados y asociaciones interponen la acción a sabiendas que el demandado no es responsable. ${ }^{27}$ Es una realidad que en toda jurisdicción que contemple procedimientos de acciones colectivas, ha existido controversia vigorosa acerca de sus virtudes y vicios. Sólo a manera de ejemplo, si la agregación reduce el costo de litigar también puede promover reclamaciones frívolas que resultan en un gasto innecesario de recursos judiciales y que imponen cargas financieras inapropiadas en demandados que, a la postre, serán asumidas por —o traspasadas a— los consumidores. $^{28}$

Entonces cabe resaltar que los elementos característicos de los procedimientos judiciales descritos, comprenden efectos positivos y negativos. Para algunos autores, la consolidación de demandas similares en una acción grupal aumenta la posibilidad de litigios y también la responsabilidad potencial de causantes de daños quienes de otra manera no serían demandados por víctimas; así, podría decirse que permite mejorar el desbalance existente entre demandantes y demandados en diferentes áreas del Derecho. Como instrumento jurídico, genera resultados que logran alterar el balance de poder y la distribución de riqueza entre los diferentes actores sociales - empresas, firmas, ciudadanos, consumidores_- por lo que su alcance de extiende en términos de impacto social. ${ }^{29}$ Las alegaciones de empresas demandadas vía acciones grupales han sido constantes y consistentes en cuanto que dichos litigios son una carga enorme en la actividad su actividad propia, que resulta en derroche de recursos y consecuencias dañinas en general para con toda la economía. ${ }^{30}$

\section{ELEMENTOS Y ASPECTOS DISTINTIVOS DE LOS PROCEDIMIENTOS COLECTIVOS}

Varias jurisdicciones establecen los procedimientos grupales en la ley; otras no los contemplan como tal, pero en cambio si reconocen derechos colectivos en sus constituciones y leyes — protección de consumidores, el medio ambiente- que han llevado a jueces permitir litigios grupales alrededor de tales derechos. Además de su fuente de regulación, las leyes y reglas sobre estas acciones difieren en aspectos importantes; así, en algunos países —Canadá y Australia, además de los Estados Unidos_-

27 Myriam Duban y Sophie Harnay, «The Economics of Class Actions: Fundamental Issues and New Trends», en: Eva Lein y Duncan Fairgrieve (eds.), Collective Redress in Europe - Why and How? London, British Institute of International and Comparative Law, 2015, p. 39.

28 Deborah Hensler, «The Global Landscape of collective Litigation», Op. cit., pp. 9-10.

29 Alberto Cassone y Giovanni Ramello, «Private Club and Public Goods: the Economic Boundaries of Class Action Litigation», Op. cit., pp. 103-104.

30 Linda Mullenix, «Ending Class Actions as we Know Them», Emory Law Journal, Op. cit., p. 416.

(C) UNED. Revista de Derecho Politico 
la regla es trans-sustantiva, es decir que la acción puede ser instaurada en toda circunstancia que permita reclamos individuales. ${ }^{31}$

Otro rasgo distintivo se refiere a los sujetos legitimados para iniciar y continuar el procedimiento; en jurisdicciones de common law cualquier miembro de la clase o grupo puede representarla, siempre que se adecúe a los intereses de los demás. En la mayoría de jurisdicciones civilistas la legitimación privilegia - y hasta en algunos casos restringe - a una o pocas asociaciones previamente habilitadas para representar al grupo, o a fundaciones cuyo propósito específico es iniciar la acción. Otros sistemas limitan la legitimación activa a funcionarios u agencias públicas para cierto tipo de acciones grupales. ${ }^{32}$

La representación de intereses por organizaciones y asociaciones permite mitigar el riesgo de que algunas categorías de personas no lograren proteger sus derechos, pues el demandante potencial no puede litigar en nombre propio debido a incompetencia o falta de recursos financieros. Allí la organización opera como agente que busca la satisfacción del interés público — por sobre el individual—. ${ }^{33}$ Ante la posible objeción de entregar control 'ideológico' o de agenda total a una determinada organización, una solución que cabe es abrir la posibilidad a un catálogo más amplio de organizaciones que enarbolen diferentes corrientes ideológicas. Y en aquellos sistemas sin cuota litis, en el que el perdedor paga todo, resulta en que ningún individuo querrá ser representante del grupo, por lo que las organizaciones cuentan con el presupuesto para cubrir los litigios. ${ }^{34}$

Respecto a la pertenencia del grupo, algunas jurisdicciones contemplan la solicitud individual — declaración de aquél que cumpla los requisitos para ser parte del mismo (opt in); en otras, toda persona que cumpla la definición para ser parte del grupo es considerada parte de este, salvo que declare formalmente que no quiere hacer parte de la acción (opout). Ambas tipologías obligan en la sentencia a los miembros del grupo, lo que significa una prohibición para litigar individualmente los asuntos decididos o conciliados en la acción grupal. Y en los sistemas que restringen legitimación a asociaciones u organizaciones, la sentencia obliga a éstas o a sus miembros. ${ }^{35}$ Desde el punto de vista económico algunos riesgos podrían ser mitigados por la regulación de las acciones grupales; el problema de oportunismo, que aparece cuando el modelo beneficia a miembros pasivos que no contribuyen en nada al litigio espe-

31 Deborah Hensler, «The Global Landscape of collective Litigation», Op. cit., pp. 3-7.

32 Deborah Hensler, «The Global Landscape of collective Litigation», Op. cit., p. 7.

33 Alberto Cassone y Giovanni Ramello, «Private Club and Public Goods: the Economic Boundaries of Class Action Litigation», Op. cit., p. 105.

34 Samuel Issacharoff y Geoffrey Miller, «Will aggregate litigation come to Europe?», en: Jurgen Backhaus y Alberto Cassone, (eds.), The Law and Economics of Class Actions in Europe, Northampton, Elgar, 2012, pp. 57-62.

35 Deborah Hensler, «The Global Landscape of collective Litigation», Op. cit., p. 8. 
rando que otros inicien el proceso, puede resolverse al contemplar plazos para que se instauren acciones indemnizatorias para así presionar al grupo. ${ }^{36}$

En los Estados Unidos existen diferentes métodos para calcular los honorarios de abogados en class actions. En el primero, conocido como lodestar, los honorarios se determinan a partir del número de horas invertidas en el caso, luego computadas por el juez con el valor razonable de ellas según el trabajo; el segundo, consiste en un porcentaje de la suma dineraria recuperada; el tercero es una combinación de éstos, dado que permite calcular honorarios sobre un porcentaje de la indemnización o compensación, que el juez luego contrasta para con el método lodestar, evitando así que se la retribución sea excesiva. ${ }^{37}$ Los incentivos son así diferentes para el abogado, pues en el primer método buscará facturar el mayor número de horas, prolongando el litigio; por el contrario, en el segundo buscará conciliar lo más pronto posible y por la mayor cantidad dineraria, la cual será siempre menor a la reclamada inicialmente por la clase o grupo. ${ }^{38}$

Al respecto, el modelo de cuota litis promueve la formación de un grupo o clase de forma poco costosa, ya que permite al abogado litigar con la promesa de recibir un porcentaje de la suma a recibir en caso de ganar. Si dicha remuneración se restringe en caso de conciliación, entonces el interés del grupo puede fortalecerse. El pago de honorarios por hora también puede racionalizarse al limitar la cantidad por hora, previniendo así que el abogado dedique mayor tiempo al caso para aumentar su remuneración. Ahora bien, de acuerdo con Shaefer sin importar el modo de remuneración, los abogados siempre buscarán iniciar demandas temerarias y lograr conciliaciones desventajosas para los miembros del grupo. ${ }^{39}$ No obstante, para Silver es posible que el juez pueda controlar litigios frívolos al permitir acciones que sólo busquen algún bien para el grupo y la sociedad, y en el que los honorarios se calculen por porcentaje; ${ }^{40}$ y de cualquier manera, el establecimiento de honorarios altos o bajos de parte del juez, impactará la inclinación de los abogados para iniciar ese tipo de acciones. ${ }^{41}$

En cuanto a la tipología de sentencias, algunas jurisdicciones contemplan solo sentencias declarativas y medidas cautelares, mientras que otras comprenden sentencias condenatorias y reconocimiento de indemnizaciones. En aquellas jurisdicciones donde los miembros de la clase o grupo no pueden obtener reparación monetaria, la

36 Astrid STADlER, «Foreword», en: Eva Lein y Duncan Fairgrieve (eds.), Collective Redress in Europe - Why and How?, London, British Institute of International and Comparative Law, 2015, p. XIII.

37 Geoffrey Miller, Theodore Eissemberg y Roy Germano, «Attorneys' Fees in Class Actions 2009-2013», Op. cit., p. 7.

38 Thomas Ulen, «The Economics of Class Action Litigation», Op. cit., p. 83.

39 Myriam Duban y Sophie Harnay, «The Economics of Class Actions: Fundamental Issues and New Trends», Op. cit., p. 42.

40 Charles Silver, «Due Process and the Lodestar Method: You Can't Get There from Here», Tulane Law Review, vol. 74, 2000, p. 1812.

41 Charles Silver, «Is the Price Right? An Empirical Study of Fee-Setting in Securities Class Actions», Op. cit., p. 1375. 
sentencia declarativa que afirma que el demandado ha violado la ley habilitará a éstos para solicitar la reparación en litigios sucesivos. ${ }^{42}$

Adicional a la discusión de una política pública relativa a los procedimientos grupales y a sus consecuencias, y a la revisión del modelo remuneratorio de los abogados, la doctrina ha identificado posibilidades de mejora en la reformulación de tales instrumentos. Así, se destaca como importante incluir salvaguardas dentro de los mecanismos procesales colectivos, que entre otras pueden ser: de un lado, que el juez sea garante contra reclamaciones frívolas y sin mérito; de allí la importancia del control judicial por jueces debidamente capacitados para prevenir el abuso de estas acciones, mediante la comprobación de la existencia genuina del grupo y de un interés común suficiente y congruente. Además, constatar que la acción invocada realiza efectivamente el interés de la justicia, y que es el instrumento pertinente que desplaza a otros disponibles para los demandantes y sus reclamaciones. Y de otro, frente a la legitimación activa es crítico que exista control sobre el accionante que lidere reclamaciones colectivas o grupales; es cuestión de justicia y lógica el que el manejo de estas acciones esté en manos de aquellos que hayan sufrido el daño, y no en las de otras que sólo buscan ganancia personal. ${ }^{43}$

\section{RÉGIMEN JURÍDICO DE LAS ACCIONES DE CLASE EN ESTADOS UNIDOS}

La regulación normativa federal vigente en Estados Unidos se encuentra en la Regla 23 del Procedimiento Civil Federal. En ella se establecen de manera explícita cuatro requisitos que han de concurrir en toda class action, los cuales — de acuerdo los parámetros establecidos en el año 1982 por la Corte Suprema en la sentencia General Telephone Co. of Soutbwest v. Falcon - el juez debe someter a un análisis riguroso para que la clase pueda ser certificada. El primero de tales requisitos explícitos es la numerosidad — numerosity — en cuanto «la clase es tan numerosa que el litisconsorcio de todos los miembros es impracticable.» El término 'impracticable' se entiende como difícil, más no imposible. Los otros tres requisitos para la conformación del grupo se denominan 'comunidad' —existencia de al menos una cuestión de hecho o de derecho común a todos los miembros_-, 'tipicidad' — la reclamación del representante es típica de aquella de los miembros, es decir se erige a partir de la misma teoría del hecho y del daño_- y 'adecuación de la representación. ${ }^{\text {‘4 }}$

42 Deborah Hensler, «The Global Landscape of collective Litigation», Op. cit., p. 8.

43 Mira Raja y Paul Lomas, «A Lawyer's Perspective», Eva Lein y Duncan Fairgrieve (eds.), Collective Redress in Europe - Why and How? London, British Institute of International and Comparative Law, 2015, p. 75 .

44 Robert Klonoff, Class Actions and Other Multi-Party Litigation in a Nutshell, St. Paul, West Academic Publishing. 
Respecto al tamaño del grupo, la regla 23 no impone un número de miembros; por tanto, salvo disposición normativa específica — por ejemplo la establecida en la sección 4 de la CAFA en cuanto cien miembros deben concurrir para así invocar jurisdicción federal - la numerosidad ha de evaluarse caso por caso. En algunas circunstancias los tribunales han certificado clases con menos de veinte miembros, así como han negado certificaciones de clase con trescientos miembros; la práctica aceptada oscila en clases de mínimo entre veinticinco y cuarenta miembros. Es importante anotar que el juez tomará en cuenta al momento de revisar el tamaño de la clase potencial, la existencia de miembros desconocidos que pueden reclamar a futuro — según lo ha señalado la Corte Federal del Quinto Circuito-. ${ }^{45}$

La conformación del grupo se da mediante la certificación de la clase —class certification - , la cual se solicita después de iniciada la demanda. De acuerdo con la sección C de la regla 23, una vez presentada la acción como una clase, el juez determinará si ésta puede ser certificada. La pertenencia al grupo en las acciones de la regla 23 se entiende como obligatoria — mandatory —, salvo aquella acción indemnizatoria de la sección B(3). En esta última, el juez notificará — de la forma más práctica según las circunstancias, como por ejemplo vía correo o espacios publicitarios- a los miembros de la clase acerca de la certificación de la misma, y establecerá el plazo en que pueden excluirse de la acción —opt-out—. ${ }^{46}$

La regla 23 no requiere entonces la individualización de cada uno de los miembros del grupo con anterioridad a la certificación de la acción como una colectiva; y salvo el número de 100 en la CAFA, el modelo no establece número mínimo de miembros. La norma se enfoca en la rigurosidad de unos requisitos que una vez confirmados, permitirán la agrupación de personas a futuro que se someterán al resultado de la acción de clase. Es decir, no contempla la posibilidad de adhesión específica —opt-in — y sólo a manera de excepción permite la exclusión —opt-out_ . Tampoco favorece ni privilegia la legitimación en cabeza de sujetos calificados o institucionales. ${ }^{47}$

La jurisprudencia relevante a nivel federal sobre las class actions en Estados Unidos ha confirmado que estas proceden de acuerdo con las reglas establecidas por el legislador en la Regla 23, teniendo además en cuenta razones de economía procesal, división de costos, y protección de las partes en el litigio, que en su suma ahorra recursos para el sistema judicial. ${ }^{48}$ De manera general se entiende que están disponibles en cualquier controversia, para cualquier materia siempre que la conducta de derecho sustantivo no haya prescrito y que el legislador no las haya prohibido. ${ }^{49} \mathrm{Y}$ el Congreso ha intentado reformar constantemente el régimen de estas acciones, identificando

45 Ibidem.

46 Ibidem.

47 Ibidem.

48 Corte Suprema de Estados Unidos, Caso Califano v. Yamasaki, 442 U.S. 682 (1979), p. 701; Corte Suprema de Estados Unidos, Caso U.S. Parole Commission v. Geragthy, 445 U.S. 388 (1980), pp. 402-403.

49 Corte Suprema de Estados Unidos, Caso Califano v. Yamasaki, 442 U.S. 682 (1979), p. 700. 
conductas indeseables e injustas por ellas propiciadas, como es el caso de la CAFA -Class Actions Fairness Act-.

En ese orden de ideas la CAFA es uno de los pocos ejemplos en que la legislatura federal ha logrado restringir el modelo de class actions, puesto que desde el año 1973 se han dado al menos sesenta y ocho proyectos de ley con tal objeto que en su inmensa mayoría no prosperaron. ${ }^{50}$ Entre otras razones —además de la dificultad en movilizar apoyo popular frente a iniciativas legislativas que pongan en riesgo derechos ya ganados- porque las normas propuestas se dirigían a reducir considerablemente los honorarios de abogados, a permitir el cobro eventual de los honorarios de la contraparte a los demandantes y a reducir el monto indemnizatorio para éstos últimos. En definitiva a reducir incentivos y oportunidades para utilizar este tipo de acciones. ${ }^{51}$

Las decisiones judiciales han sido consistentes en limitar o restringir ese tipo de acciones en los últimos años, pues — de acuerdo a Hensler - desde sentencias de la Corte Suprema se les han cerrado las puertas; ${ }^{52}$ entonces, si bien la ley autoriza la pertenencia al grupo incluso de aquellos que no han expresado tal deseo y en pocos eventos permite la autoexclusión del mismo, por el contrario los tribunales han ejercitado escepticismo y cautela al certificar una clase. ${ }^{53}$ En ese sentido incluso han cuestionado la razonabilidad en certificar una clase de millones de personas, cuando sólo unos pocos han procedido a reclamar. ${ }^{54} \mathrm{La}$ jurisprudencia permite la entrega de indemnizaciones no reclamadas a organizaciones sin ánimo de lucro, y la discrecionalidad del juez — dentro de ciertos parámetros de experticia, tiempo, dificultad del asunto y efectividad - al momento de fijar los honorarios de los abogados. ${ }^{55}$ Igualmente ha enfatizado en que las acciones pierden su efectividad y equilibrio cuando permiten el abuso de los abogados. ${ }^{56}$

La aproximación cautelosa a las class actions evidenciada en leyes como la CAFA se observa también en la jurisprudencia; ${ }^{57}$ en ese sentido, se entiende que la inadmi-

50 Stephen Burbank y Sean Farhang, «Class Actions and the Counterrevolution Against Federal Litigation», Op.cit., p. 1507.

51 Stephen Burbank y Sean Farhang, «Litigation Reform: An Institutional Approach», University of Pennsylvania Law Review, vol. 162, 2014, pp. 1555-1565.

52 Deborah Hensler, «From Sea to Shining Sea: How and Why Class Actions are Spreading Globally», Op.cit.,p. 965.

53 Corte Federal de Distrito - Distrito Norte de Texas, Caso In re Kosmos Energy Ltd. Sec. Litig., 299. F.R.D. 133 (2014), pp. 137-138.

54 Corte Federal de Distrito - Distrito Sur de Texas, Caso In re Heartland Payment Sys., $851 \mathrm{~F}$. Supp. 2d. 1040 (2012), p. 1047.

55 Corte Federal de Distrito - Distrito Sur de Texas, Caso In re Heartland Payment Sys., 851 F. Supp. 2d. 1040 (2012), pp. 1047-1076.

56 Corte Federal de Distrito - Distrito Central de California, Caso Medranov. Modern Parking Inc., U.S. Dist. Lexis 80024 (2007), p. 18.

57 De acuerdo con Burbank y Farhang, los intentos por restringir el régimen de class actions han sido exitosos en los tribunales y no en el Congreso, porque: (i) en aquellos es más fácil alcanzar mayorías en asuntos controversiales; (ii) los jueces no están sujetos a presiones democráticas ni elecciones; (iii) las decisiones judiciales pueden hacer evolucionar conceptos jurídicos caso a caso, sin enfrentar la oposición 
sibilidad de una de estas acciones no implica la afectación ni erosión del debido proceso individual, y además que las cláusulas arbitrales de un contrato pueden válidamente prohibir el acceso a class actions y que tales cláusulas arbitrales deben entonces ser respetadas y acatadas. ${ }^{58} \mathrm{Y}$ en particular, los jueces han sido constantes en señalar la situación extrema que las class actions pueden significar para el demandado, ${ }^{59}$ en especial cuando se trata de el Estado o de alguna de sus agencias; ${ }^{60}$ como principio aparece que el remedio a alcanzar no puede ser más oneroso de lo necesario para el demandado. Han reconocido que el modelo es 'extorsivo,' pues el riesgo de una indemnización enorme presiona al demandado a conciliar, por temor a un jurado y sin importar si es responsable. Es preferible la conciliación, pues los resultados del litigio colectivo pueden ser 'terroríficas' para el demandado. ${ }^{61}$ Es un mecanismo procesal que tiene la contundencia de un mazo, por lo que el juez sólo debe autorizar su procedencia en casos apropiados. ${ }^{62}$

En ese sentido los tribunales han sido especialmente cautelosos en casos recientes donde la parte demandada es una entidad estatal, como una ciudad. Allí han reforzado las reglas de proporcionalidad, pues cuando la responsabilidad económica potencial del demandado es enorme en comparación con el daño alegado, el juez — por razones de debido proceso - no debe certificar la clase. Estas acciones no pueden configurarse en un castigo aniquilador sin relación con los daños causados, pues de lo contrario se llega a resultados absurdos. ${ }^{63}$ Entonces, la bancarrota potencial del demandado puede ser un factor a tener en cuenta por el juez para certificar o no la clase. ${ }^{64} \mathrm{Y}$ es claro que el efecto de la indemnización en una class action no puede ser paralizar o incapacitar el funcionamiento de una entidad estatal, por lo que no pueden avalarse estos mecanismos cuando representan consecuencias catastróficas para una ciudad. ${ }^{65}$ En suma, un litigio que exponga a una ciudad a la ruina, no puede configurarse como justo.

masiva a la que se ven sujetas determinados proyectos legislativos. Ver Stephen Burbank y Sean FARHANG, «Litigation Reform: An Institutional Approach», Op.cit., p. 1545.

58 Corte Suprema de Estados Unidos, Caso American Express Co. V. Italian Colors Rest., 570 U.S. 228 (2013), pp. 234-237.

59 Corte Suprema de Estados Unidos, Caso ATET Mobility v. Concepcion, 563 U.S. 333 (2011), pp. 350-352; Corte Federal de Apelaciones - Séptimo Circuito, Caso In re Rhone Poulenc Rorer Inc., 51 F.3d 1293 , p. 1298 (1995).

${ }_{60}$ Corte Federal de Distrito - Distrito Central de California, Caso Rowden v. Pacific Parking Systems, 282 F.R.D. 581 (2012), p. 587.

${ }^{61}$ Corte Suprema de Estados Unidos, Caso ATET Mobility v. Concepcion, 563 U.S. 333 (2011), p. 350.

62 Corte Federal de Distrito - Distrito Central de California, Caso Medrano v. Modern Parking Inc., U.S. Dist. Lexis 80024 (2007), p. 8.

63 Corte Federal de Distrito - Distrito Central de California, Caso Medrano v. Modern Parking Inc., U.S. Dist. Lexis 80024 (2007), pp. 8-10.

${ }^{64}$ Corte Federal de Apelaciones - Noveno Circuito, Caso Bateman v. American Multi-Cinema, Inc., 623 F.3d 708 (2010), p. 723.

65 Corte Federal de Distrito - Distrito Central de California, Caso Rowden v. Pacific Parking Systems, 282 F.R.D. 581 (2012), p. 587. 


\section{PROCEDIMIENTOS COLECTIVOS EN CHILE}

El origen de los procedimientos colectivos en Chile se enmarca — de acuerdo con la doctrina especializada - en cambios socio-jurídicos e industriales en el mundo que posibilitan la aparición de nuevos derechos e intereses calificados como 'supraindividuales;' ${ }^{\prime 6}$ realidades nuevas que requieren de mecanismos orientados a la consecución de justicia para grupos con pocos recursos, pues tal como se desprende de los debates legislativos que permitieron su adopción entonces, la protección de los consumidores carecía de instrumentos jurisdiccionales que facilitaran la defensa efectiva de sus intereses. ${ }^{67} \mathrm{~A}$ la vez que se tenía en cuenta también la idea de prevenir los abusos que se atribuyen al sistema estadounidense. ${ }^{68}$

La regulación normativa de los procedimientos colectivos en Chile está consagrada en la Ley 19496 de 1997, reformada luego en las leyes 19955 de 2004 y 21081 de 2018. Cabe señalar que son leyes sectoriales enfocadas hacia el consumo, pues se denominan de «Protección de los Derechos de los Consumidores.» Se entiende que en cuanto relaciones de consumo, dicha ley se extiende también a los ámbitos de la salud y la educación, pues el artículo 2.d somete a la norma los contratos de educación y el 2.f la contratación de los servicios de salud. Así, el artículo 1 de la norma señala como su objeto regular «las relaciones entre proveedores y consumidores, establecer las infracciones en perjuicio del consumidor y señalar el procedimiento aplicable en estas materias.»

La norma establece en el artículo 3 como derechos del consumidor la libre elección del bien o servicio, la información veraz sobre bienes y servicios ofertados, la no discriminación para acceder a estos, la seguridad en su consumo, la reparación e indemnización, y la educación para un consumo responsable. Derechos que, de acuerdo con el artículo 4, «son irrenunciables anticipadamente por los consumidores,» y que algunos sectores de la doctrina han calificado como derechos fundamentales de tercera generación. ${ }^{69}$

El título IV de la Ley menciona los procedimientos mediante los cuales se implementa la misma; de manera general las acciones judiciales que derivan de la Ley «se ejercerán frente a actos, omisiones o conductas que afecten el ejercicio de cualquiera de los derechos de los consumidores. ${ }^{70} \mathrm{Y}$ como fines del procedimiento judicial se consagra sancionar al proveedor, anular las cláusulas abusivas, obtener la prestación

66 Maite Aguirrezábal, «La Certificación de la Acción en el Procedimiento Colectivo contemplado en la Ley Chilena de Protección de Consumidores y Usuarios», Anales de la Facultad de Ciencias Jurídicas y Sociales de la Universidad Nacional de la Plata, vol. 16, 2019, p. 524.

67 Felipe Valenzuela y Sebastián Silva, «La Legitimación Activa en el Examen de Admisibilidad en los Procesos Colectivos de Consumidores», Revista Justicia y Derecho, vol. 2, 2019, pp. 97-98.

68 Agustín Barroilhet, «Class Actions in Chile», Law and Business Review of the Americas, vol. 18, 2012, p. 277.

69 Felipe Valenzuela y Sebastián Silva, «La Legitimación Activa en el Examen de Admisibilidad en los Procesos Colectivos de Consumidores», Op. cit., p. 107.

70 Ley PDC art. 50. 
de la obligación, así como también «hacer cesar el acto que afecte el ejercicio de los derechos de los consumidores, o a obtener la debida indemnización de perjuicios.» ${ }^{71}$

Estas acciones pueden ser ejercidas «tanto a título individual como en beneficio del interés colectivo o difuso de los consumidores;» y define entonces estas últimas como las acciones «que se promueven en defensa de derechos comunes a un conjunto determinado o determinable de consumidores, ligados con un proveedor por vínculo contractual. Son de interés difuso las acciones que se promueven en defensa de un conjunto indeterminado de consumidores afectados en sus derechos.» ${ }^{72}$ En ese orden de ideas es un procedimiento cuyo objeto es la protección de los intereses colectivos y difusos — nunca individuales-, en tanto que no hay acción colectiva cuando los consumidores a título individual requieren la reparación del derecho lesionado. ${ }^{73} \mathrm{La}$ Ley se refiere a la representación profesional en el artículo 50C, cuando prescribe que en las citadas acciones las partes deben comparecer con intervención de letrado o con patrocinio de abogado habilitado. Cabe anotar que la Ley faculta al juez para intervenir directamente en el desempeño del abogado dentro del procedimiento colectivo; así, «en el caso que el juez estime que las actuaciones de los abogados entorpecen la marcha regular del juicio, solicitará a los legitimados [...] que nombren procurador común [...] [y] en subsidio, éste será nombrado por el juez de entre los mismos abogados.»Y en tal caso su remuneración será fijada por el juez, el cual «regulará prudencialmente los honorarios del procurador común, [...] considerando las facultades económicas de los demandantes y la cuantía del juicio.» ${ }^{74}$

Desde el artículo 51 la Ley dispone el procedimiento especial para las acciones sobre protección del interés colectivo o difuso de los consumidores; en cuanto a la legitimación activa, el numeral 1 afirma que la acción se inicia con la demanda interpuesta por el SERNAC — Servicio Nacional del Consumidor-, una Asociación de Consumidores constituida con seis meses de antelación a la acción, o un grupo de consumidores afectados en un mismo interés de al menos 50 personas. Una vez iniciado el proceso, y de acuerdo con el numeral 3, toda persona afectada puede sumarse al grupo; en palabras de la norma, «iniciado el juicio señalado, cualquier legitimado activo podrá hacerse parte en el mismo.»

El modelo habilita al SERNAC para asumir la representación de consumidores, sin requerir acreditación alguna, y le permite además intervenir en los procesos citados. El requisito de preexistencia para las asociaciones busca dar prioridad a organizaciones con vocación de protección a consumidores, así como también afectación de personas ausentes y abusos contra demandados. Respecto al número de consumidores del grupo - noción que no cuenta con definición legal, y cuyo rasgo es la posterioridad pues aparece tras la ocurrencia del acto que afecta- se ha entendido que éste sea

71 Ley PDC art. 50.

72 Ley PDC art. 50.

73 Felipe Valenzuela y Sebastián Silva, «La Legitimación Activa en el Examen de Admisibilidad en los Procesos Colectivos de Consumidores», Op. cit., p. 102.

74 Ley PDC art. 51-7. 
lo suficientemente representativo atendiendo a los efectos de la sentencia. Y llama la atención de sectores de la doctrina el que de los legitimados, sólo al grupo se le exige la concurrencia de una afectación, por lo que ha sido calificada como una carga adicional desproporcionada. ${ }^{75}$

Una vez interpuesta la demanda, la Ley ordena —en el artículo 52 - al órgano judicial que la examine y la declare admisible, siempre que la parte demandante cuente con legitimación y que cumpla con los requisitos del Código de Procedimiento Civil; entre otros el nombre de cada uno de los demandantes, es decir prescribe individualizar a cada uno de los miembros del grupo. La admisión de la demanda equivaldría entonces en el Derecho Comparado a la certificación del grupo o la clase, de manera que implica una fase capital del proceso al determinar si la pretensión puede tramitarse por la vía colectiva; es un examen que el legislador chileno estableció para evitar un abuso del instrumento. ${ }^{76}$ De acuerdo con el artículo 26, «las acciones que persigan la responsabilidad contravencional que se sanciona por la presente ley prescribirán en el plazo de dos años, contado desde que haya cesado en la infracción respectiva.»

La Ley prescribe —en el artículo 53C — que la sentencia, al conceder las pretensiones del grupo, aborde determinados asuntos; así, habrá de declarar cómo los hechos afectaron intereses colectivos o difusos de los consumidores, la responsabilidad de los demandados y las multas que sean menester, la procedencia y monto de las indemnizaciones correspondientes, y la devolución de pagos excesivos. El mismo artículo contempla que «contra la sentencia definitiva procederá el recurso de apelación,» y el 54 establece que «la sentencia ejecutoriada que declare la responsabilidad del o los demandados producirá efectos erga omnes.»

Si bien el demandado cuenta con 30 días de plazo para efectuar las reparaciones y entregar las indemnizaciones, la Ley permite el pago de éstas en plazos cuando afecten la viabilidad económica de éste. De acuerdo con el artículo 54F, «cuando el monto global de la indemnización pueda producir, a juicio del tribunal, un detrimento patrimonial significativo en el demandado, de manera tal que pudiera estimarse próximo a la insolvencia, el juez podrá establecer un programa mensual de pago de indemnizaciones completas para cada demandante.»

La Ley establece sanciones para los casos en que se abuse de los procedimientos colectivos; así, la interposición de una acción que carezca de fundamento plausible conllevará a la sanción de los responsables, de manera tal que «la multa podrá ascender

75 Maite Aguirrezábal, «Capacidad y Legitimación del Grupo de Afectados en la Ley de Protección de Consumidores y Usuarios», Revista Chilena de Derecho Privado, núm. 31, 2018, pp. 370373; Felipe Valenzuela y Sebastián Silva, «La Legitimación Activa en el Examen de Admisibilidad en los Procesos Colectivos de Consumidores», Op. cit., pp. 103-106.

76 Maite Aguirrezábal, «La Certificación de la Acción en el Procedimiento Colectivo contemplado en la Ley Chilena de Protección de Consumidores y Usuarios», Op. cit., p. 525-526; Felipe Valenzuela y Sebastián Silva, «La Legitimación Activa en el Examen de Admisibilidad en los Procesos Colectivos de Consumidores», Op. cit., pp. 98. 
hasta 200 unidades tributarias mensuales, pudiendo el juez, además, sancionar al abogado.» ${ }^{77}$

Las Acciones Colectivas en la Jurisprudencia de la Corte Suprema de Justicia:

En diferentes decisiones la Corte Suprema chilena se ha pronunciado sobre los distintos aspectos y rasgos de los procedimientos colectivos, entre ellos el objeto de la ley, las etapas del procedimiento y el requisito de admisibilidad, la legitimación activa, y el contexto del grupo.

El objeto de la ley — de acuerdo con el alto tribunal— además de declarar infracciones y el procedimiento apropiado para sancionarlas, consiste en «regular las relaciones entre proveedores y consumidores,» protegiendo a éstos «de la desigualdad que por regla general enfrentan ante los proveedores de bienes y servicios, [...] [mediante] un conjunto de derechos que cautelen las condiciones de una mejor vinculación [...] [y] propendiendo al equilibrio entre ambos grupos de sujetos.» Ante la desprotección propiciada en la protección individual del consumidor, la legislación vigente ampara «intereses colectivos y difusos de los consumidores,» de manera que logra «la adecuada solución de [...] conflictos que involucran intereses supraindividuales [...] [y] ponen fin a las asimetrías existentes entre consumidores y proveedores. ${ }^{78}$

Se ha entendido que los consumidores y usuarios suelen encontrarse en situación de vulnerabilidad, ${ }^{79}$ por lo que la norma mejora «la eficacia de [sus] derechos [...] al estatuir [...] acciones colectivas protectoras de intereses colectivos y difusos y, al mismo tiempo, crea los procedimientos apropiados para hacerlos efectivos en justicia.» ${ }^{80} \mathrm{La}$ Corte reconoce que la salvaguarda de grupos de personas, cuyo número impide la solución judicial mediante institutos clásicos, genera una tensión que deberá resolverse a través de la adaptación « a ésta nueva realidad, demostrando de paso el carácter instrumental que tienen las instituciones procesales para la tutela del derecho material.» ${ }^{81}$ En resumen, es un fenómeno en el que se incorpora «una nueva realidad jurídica, cuyo objetivo es conceder amparo a situaciones en que la titularidad del derecho o del interés corresponde a varios sujetos conjuntamente. ${ }^{82}$

Esos objetivos trazados en la legislación se refuerzan con alusiones a la historia de su aprobación, pues la Corte observa que el Gobierno — en su momento- señalaba que en su contenido se prescribía «el equilibrar el funcionamiento del mercado incorporando la defensa de los $[\ldots]$ consumidores, $[\ldots]$ mediante herramientas procesales adecuadas [...] [con] una sentencia única.» Equilibrio que se alcanza con la participación de los afectados, «la cual no solo se debe reconocer y permitir, sino que, además, privilegiar, fomentar y ampliar, mediante una interpretación progresiva y no

77 Ley PDC art. 50-E.

78 Sentencia Corte Suprema de Chile, Rol 7183-17, 2017, considerando 4.

79 Sentencia Corte Suprema de Chile, Rol 1408-08, 2009, considerando 17.

80 Sentencia Corte Suprema de Chile, Rol 9010-12, 2013, considerando 10.

81 Sentencia Corte Suprema de Chile, Rol 1408-08, 2009, considerando 17.

82 Sentencia Corte Suprema de Chile, Rol 1297-08, 2009, considerando 8. 
restrictiva.» ${ }^{83}$ Desde otra perspectiva, se justifica la existencia de los procedimientos colectivos en el Derecho Chileno, en tanto que los intereses colectivos o difusos están subordinados al derecho subjetivo individual; así, los intereses descritos se entienden como derechos individuales homogéneos «y su forma de protección es especial u original no por la índole supraindividual del interés, sino por consideraciones únicamente prácticas: impedir que el costo de pleitear esté por sobre el provecho esperado del pleito.» ${ }^{84}$

Acerca del procedimiento, la Corte Suprema ha señalado que la sustanciación «se sujeta a las reglas del juicio sumario con ciertas particularidades y la prueba se aprecia conforme a las reglas de la sana crítica, ${ }^{85}$ y se desarrolla en tres etapas específicas; un primer momento «destinado a estudiar la admisibilidad de la acción, seguido de una fase encaminada a determinar la existencia del quebrantamiento legal y la responsabilidad del proveedor en el menoscabo de los intereses [...] de consumidores o usuarios. [...] Una tercera etapa — supeditada al resultado de la anterior - reservada a resolver lo pertinente de las compensaciones apoyadas en la sentencia declarativa de responsabilidad. ${ }^{86}$

Y en ese sentido a clarificado que la etapa de admisibilidad no es un momento contencioso, sino que implica una verificación por el juez de los sujetos legitimados y de «que la demanda contenga una exposición clara de los hechos y fundamentos de derecho que justifiquen razonablemente la afectación del interés colectivo o difuso de los consumidores.» ${ }^{87}$

El alto tribunal se ha referido a los sujetos legitimados en las acciones; así, la norma «pretendió estructurar un procedimiento expedito para la asociación de consumidores [...] a fin de estimular la creación de organizaciones que representen [...] [sus] derechos en todo el territorio nacional, permitiéndoles ejercer [...] la representación de los intereses colectivos y difusos. ${ }^{88}$ No obstante, debe existir alguna coherencia entre los intereses que la organización declare proteger y la demanda incoada; en ese sentido, es necesario que la «asociación cuyo objeto sea la defensa de los consumidores [tenga conexión] efectivamente con la conducta desplegada por la empresa a la cual se demanda o, por lo menos, que se trate de una asociación de defensa general de intereses de los consumidores.» ${ }^{89}$

La Corte interpreta el instituto de la legitimación como un límite al abuso de los procedimientos colectivos, en cuanto que «no parece tener asidero una interpretación de los preceptos que propugne la existencia de juicios en los que quienes deducen la acción carezcan de todo vínculo con el grupo de quienes son lesionados.» Y en lo que

83 Sentencia Corte Suprema de Chile, Rol 1408-08, 2009, considerando 17.

84 Sentencia Corte Suprema de Chile, Rol 1904-06, 2006, considerando 5.

85 Sentencia Corte Suprema de Chile, Rol 9010-12, 2013, considerando 11.

86 Sentencia Corte Suprema de Chile, Rol 7183-17, 2017, considerando 5.

87 Sentencia Corte Suprema de Chile, Rol 7183-17, 2017, considerando 6.

88 Sentencia Corte Suprema de Chile, Rol 1297-08, 2009, considerando 9.

89 Sentencia Corte Suprema de Chile, Rol 1904-06, 2006, considerando 2. 
respecta a las asociaciones de consumidores, para éstas contar con legitimación «requieren una vinculación sustantiva entre, al menos, algunos de sus miembros y la pretensión que reclaman.» ${ }^{90}$

En cuanto al grupo como sujeto legitimado, se ha declarado que no se le puede obligar a organizarse como asociación con personalidad; sin embargo, «si le es exigible que den cumplimiento estricto a la forma de comparecencia, por cierto especial, [...] esto es que se acredite de manera indefectible que quienes inician el procedimiento constituyen un grupo de consumidores no inferior a cincuenta personas, debidamente individualizados, y afectados todos por un mismo interés.» ${ }^{91}$ Grupo compuesto por individuos que no cuentan con estructura previa y que «se agrupan después de producidos los actos que provocan el conflicto jurisdiccional y que cobra existencia con motivo de la afectación de los derechos e intereses de cada uno de ellos, que es lo que les otorga la cohesión.» ${ }^{92}$

\section{PROCEDIMIENTOS COLECTIVOS EN MÉXICO}

Previo al régimen actual, las acciones colectivas existían en el sistema mexicano para asuntos laborales y agrarios, así como también para la protección del consumidor $;^{93}$ su marco actual se justifica — según la doctrina— en el acceso a la justicia de las personas menos favorecidas, la implementación de controles de calidad en la cadena productiva y distributiva de bienes y servicios, y la necesidad de prevenir resultados contradictorios en sentencias de casos tramitados individualmente. ${ }^{94}$

La regulación normativa de los procedimientos colectivos en México tiene fundamento constitucional — reforma alcanzada en el año 2010 - en el parágrafo tercero del artículo 17 de la norma fundamental, según el cual «El Congreso de la Unión expedirá las leyes que regulen las acciones colectivas. Tales leyes determinarán las materias de aplicación, los procedimientos judiciales y los mecanismos de reparación del daño. Los jueces federales conocerán de forma exclusiva sobre estos procedimientos y mecanismos.» En desarrollo de la citada disposición constitucional, en agosto de 2011 se promulgó la reforma y adiciones al Código Federal de Procedimientos Civiles en el que se adicionó el libro V, denominado «De las Acciones Colectivas.»

90 Sentencia Corte Suprema de Chile, Rol 1904-06, 2006, considerando 5.

91 Sentencia Corte Suprema de Chile, Rol 1408-08, 2009, considerando 19.

92 Sentencia Corte Suprema de Chile, Rol 7183-17, 2017, considerando 9.

93 José Ovalle, «Legitimación en las Acciones Colectivas», Op. cit., p. 1084; Juan Manuel Gómez, «La Contribución de las Acciones Colectivas al Desarrollo Regional desde la Perspectiva del Derecho Social», Cuestiones Constitucionales, núm. 30, 2014, p. 60.

94 Paula García Villegas, «Las Acciones Colectivas. Sus Generalidades», Edgar Elías Azar (ed.), Reforma Constitucional en Materia de Derechos Humanos: Un Enfoque desde la Administración de Justicia, México, Tribunal Superior de Justicia del Distrito Federal, 2012, pp. 109-110. 
La competencia sobre las acciones colectivas es limitada a los tribunales federales y su alcance es sectorial, pues la ley se refiere a la «defensa y protección de los derechos e intereses colectivos» pero «solo podrán promoverse en materia de relaciones de consumo de bienes o servicios, públicos o privados y medio ambiente.» ${ }^{95} \mathrm{El}$ artículo 580 consagra los derechos protegidos mediante las acciones - aunque no los enumera, evento criticado por sectores de la doctrina- $;{ }^{96}$ de un lado habla de derechos e intereses difusos y colectivos — de naturaleza indivisible cuyos titulares son una colectividad de personas indeterminada o determinable, relacionadas por circunstancias de hecho o derecho comunes - y del otro derechos e intereses individuales de incidencia colectiva — de naturaleza divisible cuyos titulares son individuos integrantes de una colectividad de personas, determinable, relacionadas por circunstancias de derecho-.

La competencia federal sobre los procedimientos ha sido criticada, pues las transgresiones de grupos marginados socialmente suelen darse en esferas de competencia local y municipal, y la tutela de asuntos ambientales y ecológicos es una materia concurrente entre los diversos niveles de autoridad. ${ }^{97}$ Se ha entendido que las materias abarcadas pueden — vía analogía — incluir también la protección de la salud o del patrimonio cultural, si bien se ha señalado la ausencia de un enfoque diferencial para sectores vulnerables como adultos mayores, personas con discapacidad y pueblos indígenas. ${ }^{98}$

La ley diferencia tres tipos de acciones colectivas, señaladas en el artículo 581; el primer tipo es la acción difusa, de naturaleza indivisible y atribuida a una colectividad indeterminada, ${ }^{99}$ cuyo fin es la protección de derechos e intereses difusos mediante la restitución de las cosas al estado original, son que exista vínculo jurídico entre el demandado y el grupo. El segundo tipo es la acción colectiva en sentido estricto, de naturaleza indivisible y atribuida a una colectividad determinada o determinable con base en circunstancias comunes, cuyo fin es la protección de los derechos e intereses colectivos mediante la reparación del daño causado, que se sustenta en el vínculo jurídico común entre el grupo y el demandado. Y el tercer tipo es la acción individual homogénea, de naturaleza divisible y atribuida a un grupo compuesto por individuos con base a circunstancias comunes, cuyo fin es la protección de derechos e intereses

95 CFPC art. 578.

96 Juan Manuel Gómez, «La Contribución de las Acciones Colectivas al Desarrollo Regional desde la Perspectiva del Derecho Social», Op. cit., p. 79.

97 Marisol Anglés HernándeZ, «Acciones Colectivas en Materia de Protección Ambiental, Fallas de Origen», Boletín Mexicano de Derecho Comparado, núm. 144, 2015, p. 914; Juan Manuel GómEZ, «La Contribución de las Acciones Colectivas al Desarrollo Regional desde la Perspectiva del Derecho Social», Op. cit., p. 67.

98 Paula García Villegas, «Las Acciones Colectivas. Sus Generalidades», Op. cit., p. 113; Juan Manuel Gómez, «La Contribución de las Acciones Colectivas al Desarrollo Regional desde la Perspectiva del Derecho Social», Op. cit., p. 68.

99 Según Ovalle, el adjetivo «indeterminada» se refiere a los miembros 'indeterminados' de la colectividad, pues de lo contrario se afectaría el debido proceso del demandado. Ver José Ovalle, «Legitimación en las Acciones Colectivas», Op. cit., p. 1085. 
individuales de incidencia colectiva mediante el cumplimiento forzoso de un contrato o su rescisión.

La representación profesional mediante abogado es requerida cuando los accionantes son una colectividad o una asociación civil; el artículo 586 ordena que dicha representación «deberá ser adecuada,» y tiene dicho carácter siempre que el representante: (i) obre con diligencia, buena fe y pericia; (ii) no esté inmerso en situaciones de conflicto de interés; (iii) no haya promovido ni esté promoviendo de manera reiterada acciones colectivas frívolas o temerarias; (iv) no promueva acciones colectivas con fines de lucro, electorales, proselitistas, de competencia desleal o especulativos; (v) no haya actuado con impericia, negligencia o mala fe en acciones colectivas.

En el evento que el abogado faltare a los requisitos precedentes, el juez podrá removerlo y remitirá el expediente al Consejo de la Judicatura Federal para que se apliquen las sanciones correspondientes. De acuerdo con el artículo 617 los honorarios del abogado podrán ser hasta del $20 \%$ de la cantidad cuantificada, y serán liquidados en ejecución de sentencia para lo cual — según el artículo 618 — «el juez tomará en consideración el trabajo realizado y la complejidad del mismo, el número de miembros, el beneficio para la colectividad respectiva y demás circunstancias que estime pertinente.»

La legitimación activa en las acciones se atribuye según el artículo 585, a cuatro organismos públicos — Procuraduría Federal de Protección al Consumidor, Procuraduría Federal de Protección al Ambiente, Comisión Nacional para la Protección y Defensa de los Usuarios de Servicios Financieros, y Comisión Nacional de Competencia-, una colectividad de al menos 30 miembros a través de su representante común, las asociaciones civiles sin fines de lucro creadas al menos con un año de antelación a la acción, y el Procurador General de la República. En ese sentido, se han discutido tanto la exclusión de organismos estatales y municipales que por su naturaleza están más cerca de las problemáticas que protege la ley, así como la exigencia de un número elevado de miembros en la colectividad. ${ }^{100}$

Una vez admitida la demanda por el juez, y notificada por medios idóneos a los miembros de la colectividad, éstos podrán adherirse a la parte demandante a través de una comunicación expresa al representante de aquella. El plazo para la adhesión al grupo es amplio, pues la ley dispones en el artículo 594 que podrán hacerlos «durante la substanciación del proceso y hasta dieciocho meses después posteriores a que la sentencia haya causado estado o en su caso, el convenio judicial adquiera la calidad de cosa juzgada.» El artículo 584 establece como plazo de prescripción de las acciones colectivas el de 42 meses contados a partir de la causación del daño.

Interpuesta la demanda, el juez examinará y certificará los requisitos de procedencia —entre otros, que los hechos dañosos correspondan a materias de remedio

100 Marisol Anglés Hernández, «Acciones Colectivas en Materia de Protección Ambiental, Fallas de Origen», Op. cit., p. 917; Juan Manuel Gómez, «La Contribución de las Acciones Colectivas al Desarrollo Regional desde la Perspectiva del Derecho Social», Op. cit., p. 80. 
colectivo, que sean comunes a los miembros del grupo, que existan al menos 30 miembros en el grupo y que los demás sean determinables, que la vía colectiva sea más conveniente que la acción individual—, y que escrito contenga los nombres de los miembros del grupo promotor de la acción. ${ }^{101}$ Certificados los requisitos, el juez procederá a admitir la demanda, ${ }^{102}$ lo que equivaldría entonces en el Derecho Comparado a la certificación del grupo o la clase.

La ley dispone que la sentencia se dicte dentro de los 30 días siguientes a la audiencia final, ${ }^{103}$ y esta «deberá resolver la controversia planteada por las partes conforme a derecho.» ${ }^{104}$ Respecto a las acciones colectivas en sentido estricto y a las individuales homogéneas, «el juez podrá condenar al demandado a la reparación del daño [...] así como a cubrir el los daños en forma individual a los miembros del grupo.» ${ }^{105}$ El demandado, según el artículo 607, cuenta con un plazo prudente para cumplir con la sentencia fijado en ésta. Y de manera algo curiosa, pues lo prescribe para las medidas cautelares y no para el resultado final del litigio, el artículo 611 señala que «el juez deberá valorar además que con el otorgamiento de la medida, no se cause una afectación ruinosa al demandado.»

Los Procedimientos Colectivos en la Jurisprudencia de la Suprema Corte de Justicia:

Diferentes rasgos de los procedimientos colectivos han sido abordados por la Suprema Corte de Justicia de la Nación en su jurisprudencia; entre otros, se ha pronunciado sobre el marco regulatorio tanto constitucional como legal, su objeto y la legitimación activa. De acuerdo con el alto tribunal «es pertinente recordar que las acciones colectivas son relativamente novedosas en el ordenamiento jurídico mexicano,» establecida por el constituyente como «un paso vital hacia el mejoramiento del acceso a la justicia [...] coadyuvan[do] en la construcción de un efectivo estado de derecho.» Resalta además que fue la intención de la reforma constitucional el tutelar jurisdiccionalmente «derechos e intereses colectivos, a través de acciones y procedimientos provistos de tres características centrales: agilidad, sencillez y flexibilidad.» ${ }^{106}$

Ha señalado como otro fin pretendido por la citada reforma la ampliación del «acceso a la justicia de los ciudadanos, mediante el establecimiento de instituciones procesales que permit[iesen] la defensa, protección y representación jurídica colectivas de derechos e intereses de los miembros de una colectividad o grupo dentro de la

101 De acuerdo con Anglés y Gómez, los requisitos de admisión de la demanda son excesivamente rigurosos y resultan en obstáculos para el proceso. Ver Marisol AngLÉs Hernández, «Acciones Colectivas en Materia de Protección Ambiental, Fallas de Origen», Op. cit., p. 918; Juan Manuel GómEZ, «La Contribución de las Acciones Colectivas al Desarrollo Regional desde la Perspectiva del Derecho Social», Op. cit., p. 81.

102 CFPC arts. 587-592.

103 CFPC arts. 596.

104 CFPC art. 603.

105 CFPC art. 605.

106 Suprema Corte de Justicia, Sentencia 4/2018, Fundamento 1. 
sociedad.» ${ }^{107} \mathrm{Y}$ en orden a alcanzar dichos fines, se identifican como tres los objetivos de tales acciones, a saber proporcionar economía procesal, garantizar acceso a la justicia y seguridad jurídica, y generar un efecto social respecto a la disuasión de abusos.

La economía procesal se logra mediante un sistema eficiente en el que una acción única acumula pretensiones individuales respecto a los mismos derechos, lo que promueve «ahorro de tiempo y recursos materiales en general, no sólo para la colectividad afectada y su contraparte, sino también para las instituciones encargadas de la impartición de justicia.» ${ }^{108}$ Las acciones colectivas permite el acceso al aparato judicial de pretensiones pequeñas, que son incosteables de manera individual, situando « a ambas partes del litigio en una posición de igualdad, [...] [protegiendo] los intereses de personas que no tienen los medios necesarios para hacer valer sus derechos en juicio, sea por falta de conocimiento, iniciativa, independencia u organización.» ${ }^{109}$ Y además desincentivan conductas abusivas e ilícitas de agentes económicos pues al ser éstas «combatidas colectivamente, el monto de dicha reclamación [en sentencias favorables a grupos afectados] puede ser mayor al beneficio obtenido ilícitamente.» ${ }^{110}$

No obstante resaltar que la regulación legal de las acciones «constituye una suerte de contenido mínimo que materializa el derecho a la tutela jurisdiccional efectiva en este tipo de asuntos,» las decisiones judiciales han encontrado dos elementos concomitantes en la intención del legislador; de un lado, son procedimientos que se erigen «como mecanismo eficaz para cambiar las conductas antijurídicas de las sociedades mercantiles e inclusive las malas prácticas gubernamentales.» ${ }^{111} \mathrm{Y}$ del otro, éstos se dirigen «a proteger la defensa de los intereses colectivos, pero a través de reglas y mecanismos que evi[tan] el abuso de dichos medios de defensa.» ${ }^{112}$

De manera más concreta ha declarado que «el objeto del proceso es la defensa de un derecho colectivamente considerado, [... [ [la cual] requiere precisamente de una acción de grupo o concertada, es decir, en la que coincidan varios individuos;» así tiene como presupuestos a un conjunto de personas promotores de la acción, favorecer la defensa de los derechos pertenecientes a la colectividad, y prevenir los costos adjuntos a juicios individuales. ${ }^{113}$

Sobre la legitimación la Corte ha declarado que «la titularidad del derecho siempre recae en la colectividad representada, $[\ldots]$ con independencia de que la represente uno de los entes públicos [...], de que lo haga una asociación civil, o de que actúe por medio de un representante.» ${ }^{114} \mathrm{Y}$ dado que no se trata de cualquier grupo o colecti-

107 Suprema Corte de Justicia, Sentencia 28/2013, Fundamento 54.

108 Suprema Corte de Justicia, Sentencia 28/2013, Fundamento 56.

109 Suprema Corte de Justicia, Sentencia 28/2013, Fundamento 56.

110 Suprema Corte de Justicia, Sentencia 28/2013, Fundamento 56.

111 Suprema Corte de Justicia, Sentencia 4/2018, Fundamento 1.

112 Suprema Corte de Justicia, Sentencia 34/2013, Fundamento 5.1.

113 Suprema Corte de Justicia, Sentencia 34/2013, Fundamento 5.1.

114 Suprema Corte de Justicia, Sentencia 4/2018, Fundamento 2. 
vidad, sino la «reconocida por el legislador como aquella que puede defender sus derechos en juicio,» entonces se justifica que la norma exija «que la misma esté conformada por al menos treinta personas.» ${ }^{115}$ En resumen, «la titularidad del derecho no se circunscribe únicamente a esas personas» aunque de no alcanzar «el número mínimo de miembros la acción se desecha[...] por falta de legitimación activa.» ${ }^{116}$

El alto tribunal ha resaltado que los requisitos para los accionantes están contenidos en la ley, por lo que no es dable establecer restricciones adicionales jurisprudenciales «bloqueando la vía jurisdiccional a partir de establecer candados a quienes el legislador otorgó legitimación activa.» ${ }^{117}$ Igualmente ha reconocido que el diseño de la legitimación procesal busca mantener el carácter equilibrado y proporcional del modelo, pues el fin es «evitar conductas indeseables que pudieran distorsionar la finalidad del procedimiento colectivo, o fraudes procesales que lesionen los intereses de la colectividad.» ${ }^{118}$

\section{RECAPITULACIÓN Y CONCLUSIONES}

De acuerdo con los epígrafes precedentes, en las últimas décadas se ha dado un fenómeno de expansión global de procedimientos colectivos, siendo un hecho que la mayoría de países con las economías más grandes cuentan con este tipo de mecanismos procesales. ${ }^{119}$ Los regímenes vigentes de procedimientos colectivos en Chile y México fueron adoptados en años recientes, de manera que bien podrían enmarcarse en el fenómeno descrito de expansión. De manera paralela a la adopción de tales procedimientos en todos los continentes, ${ }^{120}$ desde la doctrina especializada se han lanzado alertas sobre el desbalance y desequilibrio que se atribuyen a éstos a partir de las consecuencias económicas para los demandados, la posibilidad de litigios frívolos y temerarios, y los honorarios de los abogados.

En México y Chile, al igual que en Estados Unidos, se ha justificado la adopción de procedimientos colectivos - tanto desde la perspectiva legislativa como desde la perspectiva judicial - con argumentos alrededor de su conveniencia como práctica social, la equiparación de las partes en juicio y la realización efectiva de la justicia. Sin embargo, el análisis normativo y jurisprudencial de los citados instrumentos en estos países permite constatar una tendencia para limitar, restringir o contextualizar su alcance.

115 Suprema Corte de Justicia, Sentencia 34/2013, Fundamento 5.1.

116 Suprema Corte de Justicia, Sentencia 4/2018, Fundamento 2.

117 Suprema Corte de Justicia, Sentencia 28/2013, Fundamento 87.

118 Suprema Corte de Justicia, Sentencia 28/2013, Fundamento 88.

119 Deborah Hensler, «From Sea to Shining Sea: How and Why Class Actions are Spreading Globally», Op. cit., pp. 965-966.

120 Deborah Hensler, «The Globalization of Class Actions», The Annals of the American Academy of Political and Social Sciences, Op, cit., p. 10. 
En ese sentido puede resumirse el modelo de acciones colectivas en Chile como uno de regulación legal cuyo alcance se restringe a la protección de los consumidores, y se extiende a servicios de educación y salud; además de las materias específicas, la ley limita su ejercicio ante la infracción de derechos específicos allí enunciados. En ella se establece como finalidad de estas acciones la sanción al proveedor, anular las cláusulas abusivas, obtener la prestación de la obligación, así como también la cesación del acto que afecte el ejercicio de los derechos de los consumidores o la obtención de una indemnización de perjuicios.

El procedimiento requiere de abogado cuyos honorarios son fijados por el juez atendiendo a criterios como el trabajo realizado, el monto reclamado y la capacidad económica de los demandantes. Los legitimados para incoar el procedimiento son el SERNAC, asociaciones civiles y un grupo compuesto de al menos 50 personas. La pertenencia a éste es voluntaria y debe señalar sus miembros, aunque la ley también establece que los efectos de la sentencia son erga omnes. La acción prescribe a los dos años, y en la ley se establecen criterios de razonabilidad para que el demandado pueda cumplir con la indemnización acordada, y sanciona el abuso o temeridad en este tipo de procedimientos. Las sentencias reseñadas de la Corte Suprema evidencian un apego total a la ley, es decir, no se aprecia una variación jurisprudencial de las disposiciones normativas; en ellas se ha referido a diferentes características y aspectos de los procedimientos como su objeto, etapas, sujetos legitimados y contexto del grupo.

En síntesis, la regulación de las acciones colectivas en México tiene carácter constitucional y legal, y su alcance se restringe a la protección de los consumidores y medio ambiente. Además de las materias específicas, la ley limita su ejercicio a la infracción de los derechos e intereses difusos y colectivos — de naturaleza indivisible cuyos titulares son una colectividad de personas indeterminada o determinable, relacionadas por circunstancias de hecho o derecho comunes-, y a los derechos e intereses individuales de incidencia colectiva — de naturaleza divisible cuyos titulares son individuos integrantes de una colectividad de personas, determinable, relacionadas por circunstancias de derecho-.

La finalidad de estas acciones a sido identificada por la jurisprudencia en razones de economía procesal, de garantías de acceso a la justicia y seguridad jurídica, y de generación de un efecto social respecto a la disuasión de abusos. El procedimiento requiere de abogado cuyos honorarios de hasta un $20 \%$ sobre el monto son fijados por el juez, atendiendo a criterios como el trabajo realizado, el número de miembros y el beneficio para la colectividad respectiva. La legitimación activa la deposita la ley en cuatro entidades públicas, en asociaciones civiles y en un grupo compuesto de al menos 30 personas. La pertenencia a éste es voluntaria y puede realizarse hasta 18 meses después de ejecutoriada la sentencia. La acción prescribe a los tres años y seis meses.

En la decisión el juez podrá condenar al demandado a la reparación del daño, así como a cubrir los daños en forma individual a los miembros del grupo. La ley establece criterios de razonabilidad para que el demandado pueda cumplir con la indem- 
nización acordada, y lo protege — al menos en lo referente a medidas cautelares — para que no le se cause una afectación ruinosa. En las decisiones de la Suprema Corte estudiadas se constata un apego total a la ley —es decir, no se aprecia una variación jurisprudencial de las disposiciones normativas-; allí el alto tribunal reconoce los objetivos buscados por el constituyente y el legislador al establecer los procedimientos colectivos, así como la regulación correspondiente. Igualmente, se ha referido a los fines buscados con la norma y a los aspectos relevantes de la legitimación activa.

Como bien lo señala Hensler, los modelos de este tipo de procedimientos en el derecho comparado no son idénticos y suelen diferir en su operación. ${ }^{121}$ No obstante, al estudiar los instrumentos en Chile y México se han abordado los aspectos característicos del diseño institucional — que la misma autora denomina 'perfilamiento'como el alcance sustantivo, la legitimación procesal, la pertenencia al grupo y los efectos de la sentencia; ${ }^{122}$ adicionalmente otros rasgos como la fuente regulatoria, el objeto, el papel de los abogados y el plazo de prescripción.

Precisamente el estudio de acometido en el presente artículo permite apreciar una tendencia limitadora en los citados países, corroborada además por la consistencia en la interpretación judicial con la norma respectiva. Fenómeno que de acuerdo a la exposición realizada en las páginas precedentes, también se evidencia en los desarrollos legislativos y jurisprudenciales a nivel federal en Estados Unidos.

Las restricciones sobre estos procedimientos se enmarcan en un espectro amplio; así, se dirigen hacia la legitimación activa — prefiriendo la actuación de organizaciones y entes públicos, el escrutinio estricto de requisitos para certificar la claserarios de representación, la pertenencia a la clase, las materias objeto de la acción, la penalización del abuso, y la potencial bancarrota de la parte demandada. Entonces en los dos países latinoamericanos reseñados se aprecian mecanismos institucionales que limitan las acciones colectivas a partir de una legitimación restrictiva —que favorece sujetos calificados y que establece presupuestos estrictos para la acreditación del grupo- - de la identificación previa de los miembros del grupo — caso de Chile — , de las materias específicas sobre las que opera, de la regulación exhaustiva de la intervención de abogados — sometidos a supervisión y eventual sanción judicial—, así como también a partir de aquellos principios jurídicos que informan la operación de la acción.

121 Deborah Hensler, «The Globalization of Class Actions», The Annals of the American Academy of Political and Social Sciences, Op, cit., p. 12.

122 Deborah Hensler, «From Sea to Shining Sea: How and Why Class Actions are Spreading Globally», Op. cit., p. 972. 
Title:

Collective Redress in Latin American Comparative Law: Chile and Mexico

Summary:

Introduction. I. Collective Redress Mechanisms' Expansion. II. Cautious Approach to Collective Redress: Potential Imbalance and Abuse. III. Problematic Character of Collective Redress. IV. Collective Redress' Distinctive Elements. V. American Class Actions' System. VI. Collective Redress in Chile. VII. Collective Redress in Mexico. VIII. Recap and Conclusions.

\title{
Resumen:
}

Este artículo explora el régimen jurídico de los procedimientos colectivos en el derecho comparado latinoamericano, en específico los de Chile y México. Para ese propósito hace un barrido de la doctrina especializada sobre dichos mecanismos procesales, la cual ha identificado sus fortalezas y problemas. Así mismo se explica el modelo de Estados Unidos, debido a que es la jurisdicción donde estos instrumentos surgieron bajo la denominación de class actions. Y al revisar los regímenes chileno y mexicano se concluye que éstos se enmarcan dentro de una tendencia existente en el derecho occidental, en cuanto limitar el alcance de tales instrumentos procesales.

\begin{abstract}
:
This article explores the legal regime of collective redress in Latin American comparative law, specifically Chile and Mexico. On this sense, it does present a survey on the relevant doctrinal sources which have identified collective redress' strenghts and weakneses. Also, the American class actions' system is explained, given that it was in the U.S. where collective litigation was created. Once both Chilean and Mexican systems are studied, it is possible to assert that such are framed within a Western legal trend for limitig the scope of these procedural instruments.
\end{abstract}

\section{Palabras Clave:}

Derecho Comparado, Procedimientos Colectivos, Estados Unidos, Chile, México.

\section{Key Words:}

Comparative Law, Collective Redress, United States, Chile, Mexico. 
